\title{
Modified Perturbation and Observation Technique for Partially Shaded Photovoltaic Systems in Microgrids
}

\author{
Bader N. Alajmi and Faisal A. Alkandari
}

\begin{abstract}
A modified perturbation and observation controller for maximum power point tracking of partially shaded photovoltaic systems is proposed. The proposed controller applies scanning and storing stages to the conventional perturbation and observation technique during partial shading conditions. Moreover, the proposed system is capable to identify whether the photovoltaic system is under partial shading condition or not. The proposed system provides accurate and fast convergence to the global maximum operating point during different weather conditions. Simulation results are provided to demonstrate the validity of the controller.
\end{abstract}

Index Terms-Photovoltaic, partial shading, maximum power point tracker (MPPT), perturbation and observation.

\section{INTRODUCTION}

The development of renewable energy sources has attracted the attention of researchers. There has been significant progress in the development of renewable energy sources, such as combined heat and power (CHP) applications, solar photovoltaic (PV) modules, small wind turbines, and heat and electricity storage, where controllable loads are expected to play a significant role in future electricity supplies [1]-[5]. Photovoltaic systems are considered one of the most efficient and well-accepted renewable energy sources, due to its suitability in distributed generation, mobile applications, transportation, and satellite systems [6], [7]. However, the PV systems suffer from the nonlinearity between the output voltage and current, especially during partial shading conditions. Under partial shading conditions the characteristic curve of the PV output power and voltage will have local and global maxima. Therefore, the conventional maximum power point tracker (MPPT) such as perturbation and observation technique could fail to track the global maximum power point (MPP) [8].

Different MPPT techniques have been proposed in the literature. In [9] modified hill climbing based on observing a trajectory line is proposed. The trajectory line can identify can predict whether the PV system is partially shaded or not to save the controller from doing unnecessary scanning of the PV system under normal weather conditions. The global MPP is accurately track in this technique. However, the trajectory line are not the same for all PV modules which makes this technique work in certain conditions.

To track the global MPP under partial shading conditions,

Manuscript received September 30, 2014; revised January 12, 2015 Bader N. Alajmi is with the Public Authority for Applied Education and Training, Kuwait (e-mail: bna01@ @otmail.com).

Fisal A. Alkandari is with the Kuwait Oil Company, Kuwait. two stage MPPT is proposed in [10]. In the first stage, the conventional MPPT is used to the MPP by assuming that the $\mathrm{P}-\mathrm{V}$ curve is uniform. In the second stage, the increment resistor technique is applied to track the global MPP. In some partial shading conditions, this technique could overlook the global MPP. Moreover, the measurement of the open circuit voltage and short circuit current is required.

Heuristic optimization methods such as line search algorithm with Fibonacci sequence and practical swarm are proposed in [11]-[13]. In these techniques, large time delay is needed to allow agents to compute the global MPP which could result on long computation time.

In this paper, a modified perturbation and observation technique is proposed to track the global maximum point in a non-uniform P-I curve characteristic. The proposed controller tracks the global MPP by scanning, storing, perturbing, and observing the operating power of the PV system. Moreover, the partial shading condition is identified to save the controller from scanning the PV characteristic curve. Simulation results are provided to evaluate the effectiveness and robustness of the proposed control method.

\section{Photovoltaic Module}

PV module consists of a group of series connected solar cells to obtain sufficient working voltage [14]. Usually, the $\mathrm{PV}$ module is rated by its dc output power under standard test conditions (STC) and commercially STC specifies at irradiance of $1000 \mathrm{~W} / \mathrm{m}^{2}$ with a spectral distribution of air mass (AM) 1.5 and $25^{\circ} \mathrm{C} \mathrm{PV}$ cell temperature [15]. The PV module can be implemented from the mathematical model in eq. (1), which is derived from a cell's equivalent circuit where all cells are identical.

$$
I_{p v}=I_{p h}-I_{o}\left[e^{\left(\frac{q\left(V_{p v}+R_{s} I_{v v}\right)}{A k T_{s}}\right)}-1\right]-\frac{\left(V_{p v}+R_{s} \cdot I_{p v}\right)}{n_{s} \cdot R_{s h}}
$$

where $V_{p v}$ and $I_{p v}$ represent the PV array output voltage and current, respectively. $R_{s}$ and $R_{s h}$ are the solar cell series and shunt resistances. $q$ is the electron charge $\left(1.6 \times 10^{-19} \mathrm{C}\right) ; I_{p h}$ is the light generated current; $I_{o}$ is the reverse saturation current; $A$ is dimensionless junction material factor; $k$ is Boltzmann constant $\left(1.38 \times 10^{-23} \mathrm{~J} / \mathrm{K}\right) ; T$ is the temperature $(\mathrm{K})$; and $\mathrm{n}_{\mathrm{p}}$ and $\mathrm{n}_{\mathrm{s}}$ are the number of cells connected in parallel and series, respectively. For a given PV module, the Power-Voltage (P-V) characteristic and the Current-Voltage (I-V) characteristic under STD are shown in Fig. 1.

During shadowing conditions, the characteristic curve of the PV system in Fig. 1 is no longer valid because the radiation intensities are unequally distributed around the PV 
module or some parts of the PV module go out of service. Under partial shadowing conditions, multiple maxima exist in the PV power characteristics. The $\mathrm{P}-\mathrm{V}$ characteristic of a given PV module under STC is shown in Fig. 2.

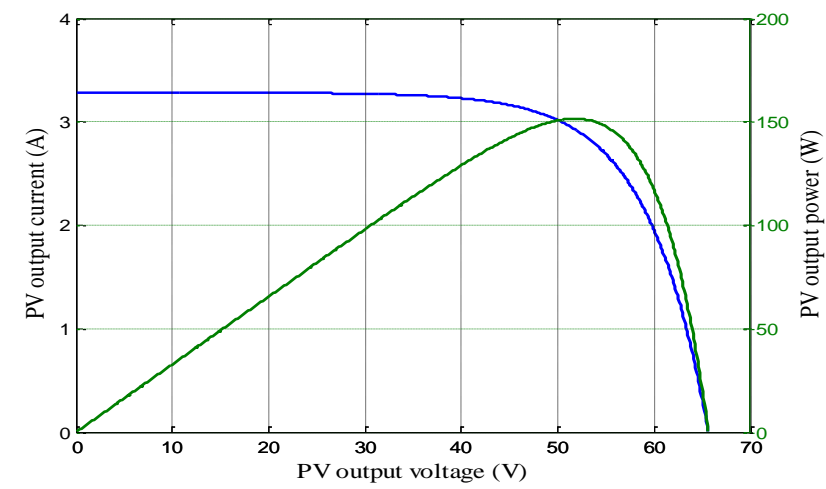

Fig. 1. The $\mathrm{P}-\mathrm{V}$ characteristic and the $\mathrm{I}-\mathrm{V}$ characteristic of a given PV module under STC.

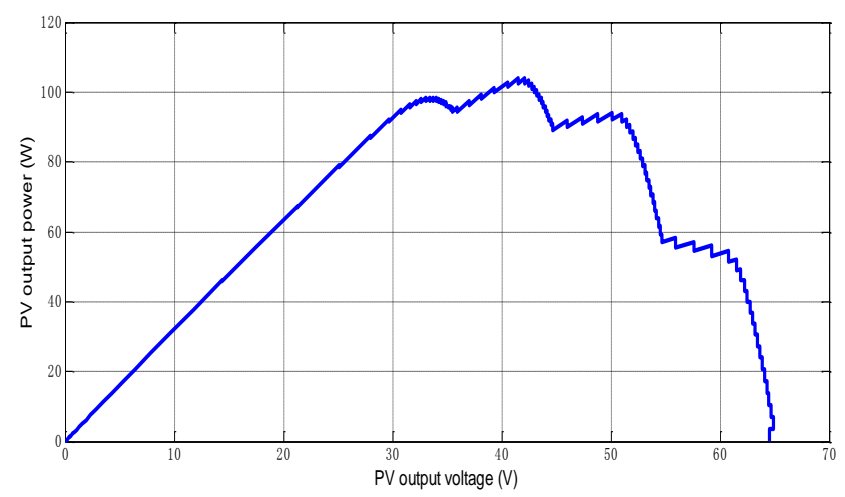

Fig. 2. The $\mathrm{P}-\mathrm{V}$ characteristic of a given $\mathrm{PV}$ module under shadowing conditions.

\section{PROPOSED METHOD}

The proposed perturbation and observation controller starts by predicting whether the PV system is under partial shading conditions or normal weather conditions. During partial shading conditions, the proposed controller will scan, store, perturb, and observe the operating power of the PV system. In contrast, the conventional perturbation and observation is applied to the PV system.

The identification of the weather condition is based on the observation from the behaviour of the PV output power variation. the variation of the PV output power is shown in Fig. 3. It is clear that the variation of the PV output power is positive during initial condition and varying weather condition at the equally distributed radiations level. On the other hand, the PV output power variation is positive during initial condition and negative during varying weather condition at the unequally distributed radiations level. Therefore, the controller is designed to sense the variation on the PV output power to decide whether to start with the scanning stage or skip it to the perturbation and observation stage. During normal weather conditions, where the variation on $\mathrm{PV}$ power is positive the conventional perturbation and observation method is applied. In case if the variation of the PV power is negative, the controller starts to scan and store the global MPP before the perturbation and observation stage.

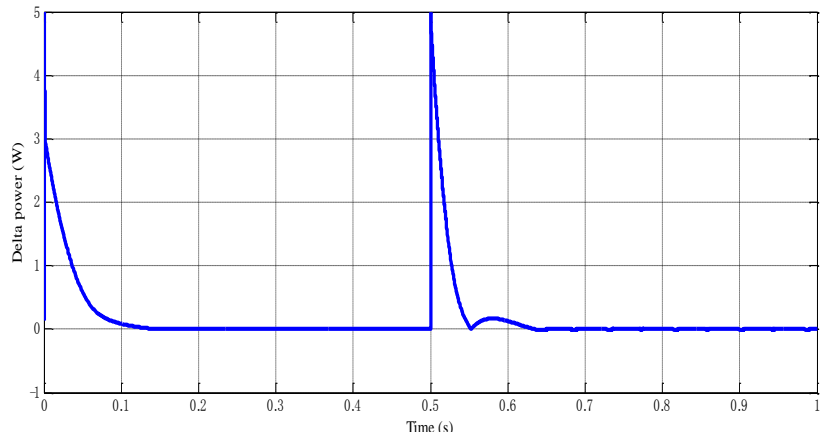

(a)

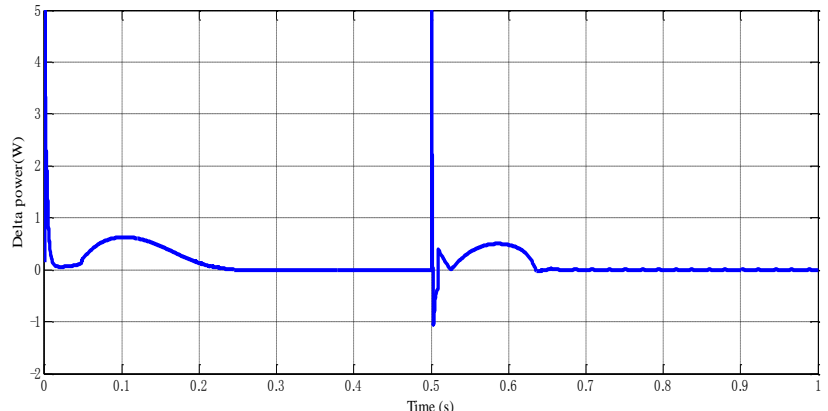

(b)

Fig. 3. a) The variation of power during normal weather conditions. b) The variation of power at partial shadowing conditions.

During partial shading conditions, the proposed controller makes a wide range search to scan and store the global MPP on the PV system. A fixed value which represents the accepted difference between the identified MPP and the operated power is stored to select the controller rules. If the difference between the IDENTIFIED MPP and the operated power is greater than the fixed value, the duty cycle is increased otherwise perturbation and observation method is applied. In this case, the algorithm guarantees that the MPPT is not imprisoned by local maxima and quickly identify the new global MPP during different weather conditions. The scanning stage does not required a long time delay because the controller scans the PV characteristic curve while the perturbation and observation is carried out. The flow chart of the proposed controller is shown in Fig. 4, where $V_{p v}$ are $I_{p v}$ are the PV output voltage and current, $D$ is the duty cycle, $P_{m}$ is the global maximum power point, and $\Delta P_{m}$ is a constant that identifies the allowable difference between the global maximum and the operating power point.

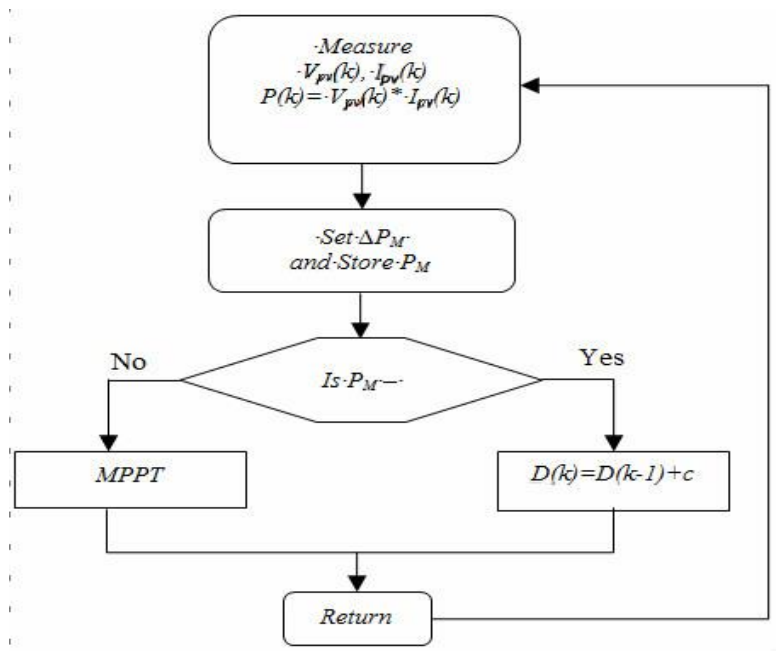

Fig. 4. The proposed method flow chart. 


\section{Simulation Results AND Discussion}

Ten series PV modules with rated power of $850 \mathrm{~W}$ is tested. The design specification and circuit parameters are shown in Table I. To validate the performance of the proposed controller, the simulation results are carried out using Matlab/Simulink. The global MPP is scanned using a large initial perturbation step.

TABLE I: DESIGN SPECIFICATION AND CIRCUIT

\begin{tabular}{|c|c|}
\hline Item & Value \\
\hline PV array rated Power, $P(W)$ & 850 \\
\hline Boost inductor, $L(H)$ & 0.3 \\
\hline Smoothing capacitor, $C(\mu F)$ & 2200 \\
\hline Output voltage, $V(V)$ & 300 \\
\hline Switching frequency, $f_{s}(k H z)$ & 4 \\
\hline
\end{tabular}

During normal weather conditions, the proposed system is tested under two radiation levels, $500 \mathrm{~W} / \mathrm{m}^{2}$ and $1000 \mathrm{~W} / \mathrm{m}^{2}$. As shown in Fig. 5, the systems successfully predict the normal weather conditions and extract the MPP under the two radiation levels.

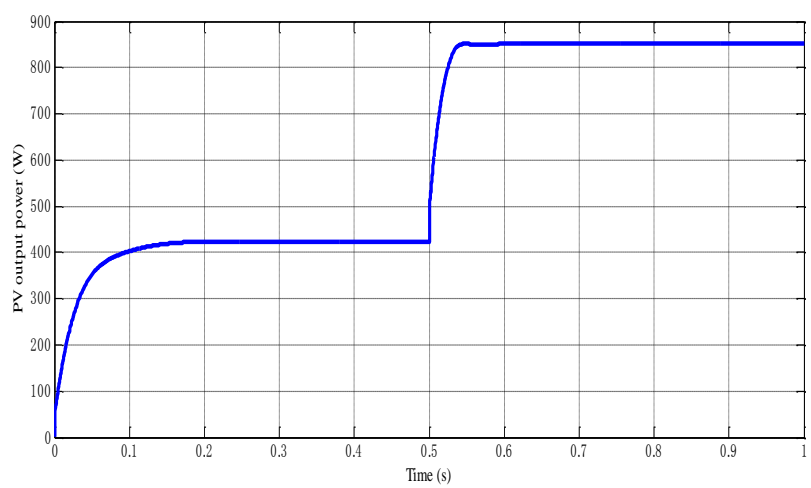

Fig. 5. PV output power characteristic for the proposed MPPT under two radiation levels.

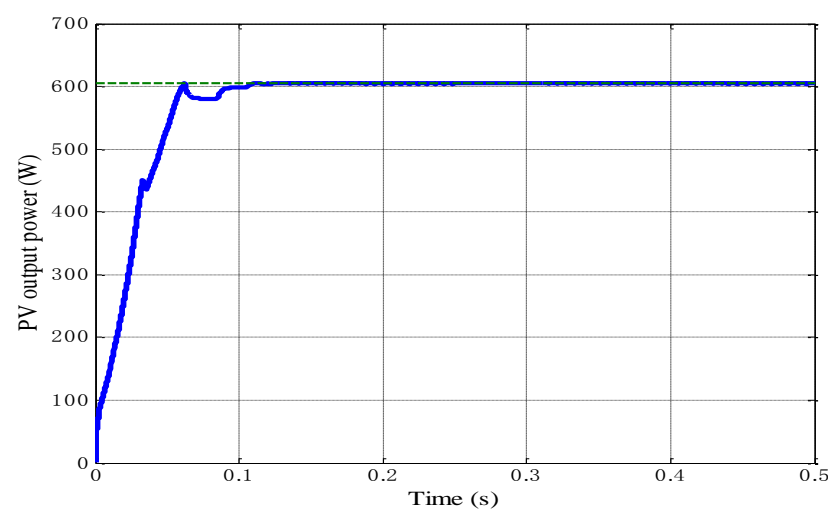

Fig. 6. PV output power for the proposed MPPT under partially shaded conditions.

During partial shading, the PV system is tested under different radiation levels; seven unshaded modules receive $1000 \mathrm{~W} / \mathrm{m}^{2}$ while the other three modules are partially shaded with a radiation level of 800,500 and $100 \mathrm{~W} / \mathrm{m}^{2}$. The PV output power is shown in Fig. 6. The proposed controller is not prevented by the local maxima from tracking the global maximum power point. Moreover, the tracking of the global maximum is fast with small oscillations at steady state. For more verification, the same partial shadowing conditions are repeated with different radiation levels on the unshaded modules; the radiation level varies from $500 \mathrm{~W} / \mathrm{m}^{2}$ to $1000 \mathrm{~W} / \mathrm{m}^{2}$ at 0.5 second and then from $1000 \mathrm{~W} / \mathrm{m}^{2}$ to $500 \mathrm{~W} / \mathrm{m}^{2}$ at 1 second. As shown in Fig. 7, the proposed controller scans and then tracks the global MPP quickly even under varying weather conditions.

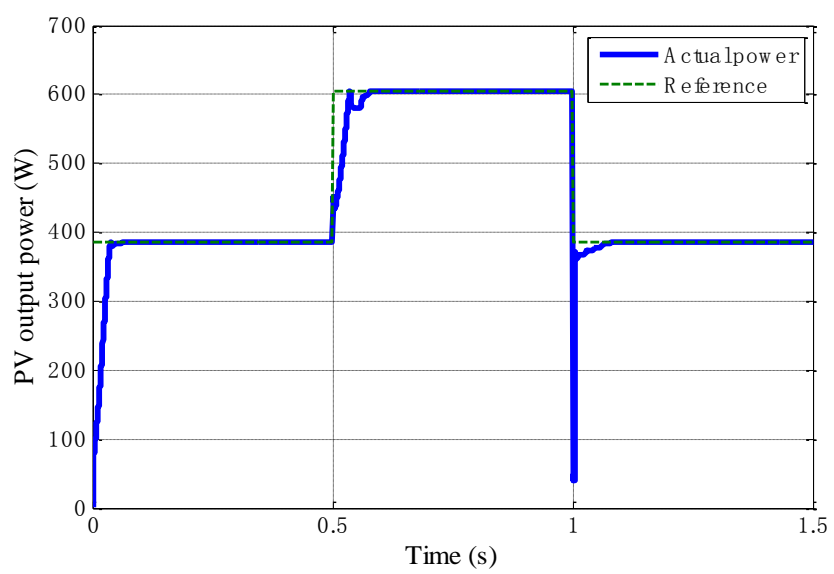

Fig. 7. Output power for a partially shaded PV system under two radiation levels along with the PV power locus.

\section{CONCLUSION}

In this paper, a modified perturbation and observation controller has been proposed to track the global MPP. The proposed MPPT was implemented by combining partial shading identifier and modified perturbation and observation which were designed to scan, store, perturb, and observe the operating power of the PV system. Matlab/Simulink simulations of a partially shaded PV system have been carried out to validate the proposed MPPT. The results show that the proposed control is able to identify whether the PV system is under normal weather conditions or partial shading conditions. Moreover, the proposed MPPT is capable of reaching the global maximum power point under any partial shading conditions.

\section{REFERENCES}

[1] I. J. Balaguer, L. Qin, Y. Shuitao, U. Supatti, and P. F. Zheng, "Control for grid connected and intentional islanding operations of distributed power generation," IEEE Transactions on Industrial Electronics, vol. 58, pp. 147-157, 2011.

[2] J. C. Vasquez, R. A. Mastromauro, J. M. Guerrero, and M. Liserre, "Voltage support provided by a droop-controlled multifunctional inverter," IEEE Transactions on Industrial Electronics, vol. 56, pp. 4510-4519, 2009.

[3] J. M. Guerrero, J. C. Vasquez, J. Matas, M. Castilla, and L. G. de Vicuna, "Control strategy for flexible microgrid based on parallel line-interactive UPS systems," IEEE Transactions on Industrial Electronics, vol. 56, pp. 726-736, 2009.

[4] J. C. Vasquez, J. M. Guerrero, A. Luna, P. Rodriguez, and R. Teodorescu, "Adaptive droop control applied to voltage-source inverters operating in grid-connected and islanded modes," IEEE Transactions on Industrial Electronics, vol. 56, pp. 4088-4096, 2009.

[5] J. M. Guerrero, J. C. Vasquez, J. Matas, L. G. de Vicuna, and M. Castilla, "Hierarchical control of droop-controlled AC and DC microgrids-A general approach toward standardization," IEEE Transactions on Industrial Electronics, vol. 58, pp. 158-172, 2011.

[6] J. M. Guerrero, F. Blaabjerg, T. Zhelev, K. Hemmes, E. Monmasson, S. Jemei, M. P. Comech, R. Granadino, and J. I. Frau, "Distributed generation: Toward a new energy paradigm," Industrial Electronics Magazine, vol. 4, pp. 52-64, 2010.

[7] K. H. Ahmed, A. M. Massoud, S. J. Finney, and B. W. Williams, "A modified stationary reference frame-based predictive current control with zero steady-state error for LCL coupled inverter-based distributed generation systems," IEEE Transactions on Industrial Electronics, vol. 58, pp. 1359-1370, 2011. 
[8] G. Lijun, R. A. Dougal, L. Shengyi, and A. P. Iotova, "Parallelconnected solar PV system to address partial and rapidly fluctuating shadow conditions," IEEE Transactions on Industrial Electronics, vol. 56, pp. 1548-1556, 2009

[9] Y. Liu, "Advance control of photovoltaic converters," Ph.D. Dissertation, Department of Engineering, University of Leicester, Leicester, UK, April 2009.

[10] K. Kobayashi, I. Takano, and Y. Sawada, "A study on a two stage maximum power point tracking control of a photovoltaic system under partially shaded insolation conditions," in Proc. Power Engineering Society General Meeting, 2003, vol. 4, p. 2617.

[11] M. Miyatake, T. Inada, I. Hiratsuka, Z. Hongyan, H. Otsuka, and M. Nakano, "Control characteristics of a fibonacci-search-based maximum power point tracker when a photovoltaic array is partially shaded," in Proc. Power Electronics and Motion Control Conference, 2004, vol. 2, pp. 816-821.

[12] N. T. Luat and L. K. Soon, "A global maximum power point tracking scheme employing DIRECT search algorithm for photovoltaic systems," IEEE Transactions on Industrial Electronics, vol. 57, pp. 3456-3467, 2010.
[13] M. Miyatake, M. Veerachary, F. Toriumi, N. Fujii, and H. Ko, "Maximum power point tracking of multiple photovoltaic arrays: A PSO approach," IEEE Transactions on Aerospace and Electronic Systems, vol. 47, pp. 367-380, 2011.

[14] D. M. Tagare, Electricity Power Generation: The Changing Dimensions, Wiley, 2011.

[15] IEEE Recommended Practice for Testing the Performance of StandAlone Photovoltaic Systems, IEEE Std 1526-2003, pp. 1-18, 2004.

Bader N. Alajmi received the B.Sc. degree and M.Sc. degree from California State University, Fresno in 2001 and 2006, respectively. He is currently working toward the $\mathrm{PhD}$ degree in electrical engineering at the Electrical and Electronic Department, Strathclyde University, Glasgow, UK. His research interests are digital control of power electronic systems, micro-grids and distributed generation, photovoltaic inverters and DC converters.

Fisal A. Alkandari received the B.Sc. degree from Kuwait University in 2006 and M.Sc. degree from Cairo University in 2008. He is currently a senior engineer at Kuwait Oil Company. His research interests are digital control of power electronic systems, power quality and renewable energy. 

Bioenergy 
